\title{
Development of a Pseudomonas syringae-Arabidopsis Suspension Cell Infection System for Investigating Host Metabolite-Dependent Regulation of Type III Secretion and Pattern-Triggered Immunity
}

\author{
Qing Yan, Conner J. Rogan, and Jeffrey C. Anderson ${ }^{\dagger}$ \\ Department of Botany and Plant Pathology, Oregon State University, Corvallis, OR 97331, U.S.A. \\ Accepted 12 November 2018.
}

\begin{abstract}
The importance of pattern-triggered immunity (PTI) in plant defense has been clearly established through genetic studies of mutants lacking functional pattern recognition receptors (PRRs) and signaling components downstream of PRR activation. Despite extensive knowledge of PRR-mediated signaling responses to pathogen-associated molecular patterns (PAMPs), little is known about which of these responses, if any, are directly responsible for limiting bacterial growth. In this work, we established a protocol for coculturing the bacterial pathogen Pseudomonas syringae pv. tomato DC3000 and Arabidopsis suspension cells. The system closely mirrors infection processes that occur in leaves, with bacteria relying on the type III secretion system (T3SS) for maximal growth and PAMP-induced plant defenses effectively limiting bacterial growth. To demonstrate the utility of this system, we investigated the molecular basis of PAMP-induced growth inhibition and discovered that T3SSassociated genes are inhibited when DC3000 is cocultured with PAMP-treated plant suspension cells. To determine the underlying mechanism of decreased T3SS gene expression, we performed metabolomics and biochemical analyses of suspension cell exudates and identified 14 metabolites that significantly increased or decreased following PAMP treatment. Citric acid, a known inducer of T3SS gene expression in DC3000, was among several organic acids decreased in exudates from PAMP-treated plant cells. Exogenous addition of citric acid increased T3SS gene expression and partially recovered growth of $\mathrm{DC} 3000$ in the presence of PAMP-treated cells, indicating that a portion of PAMP-induced defense in this system is decreased extracellular release of this metabolite. We envision that the well-defined infection conditions of this coculture system will be valuable for quantitative studies of type III effector delivery by $P$. syringae. Furthermore, this system provides a unique 'top-down' approach to unravel the molecular basis of PTI against $P$. syringae.
\end{abstract}

${ }^{\dagger}$ Corresponding author: J. C. Anderson; anderje2@oregonstate.edu

Funding: This work was funded by National Science Foundation Division of Integrative Organismal Systems grant number 1557694 to J. C. Anderson.

*The $\boldsymbol{e}$-Xtra logo stands for "electronic extra" and indicates that eight supplementary figures and three supplementary tables are published online.

○ 2019 The American Phytopathological Society
Pseudomonas syringae is a gram-negative bacterial pathogen that can cause disease on most aerial tissues of plants, including stems and fruits, and is primarily studied in the context of its ability to invade and colonize the interior space, or apoplast, of leaf tissue (Hirano and Upper 2000; Xin and He 2013). A first layer of defense encountered by $P$. syringae are pattern recognition receptors (PRRs) present in the plasma membrane of plant cells (Segonzac and Zipfel 2011). PRRs recognize conserved microbial features termed pathogen-associated molecular patterns (PAMPs) or, alternatively, microbe-associated molecular patterns that are present in the extracellular space. Well-studied PRRs include the FLAGELLIN-SENSITIVE2 (FLS2) receptor that recognizes the peptide flg22 derived from bacterial flagellin as well as the EF-TU RECEPTOR (EFR) that recognizes a peptide derived from bacterial EF-Tu protein (Gómez-Gómez and Boller 2000; Zipfel et al. 2006). Perception of PAMPs by PRRs triggers within minutes many cellular responses, including the production of reactive oxygen species, ion fluxes across membranes, activation of mitogen-activated protein kinase (MAPK) signaling pathways and altered transcription of thousands of genes (Bigeard et al. 2015; Macho and Zipfel 2014). Activation of PRRs can provide effective resistance against $P$. syringae, as evidenced by the observation that treatment of plants with PAMPs prior to infection limits the ability of pathogens to grow (Zipfel et al. 2004). Also, plants lacking functional PRRs are, in some cases, more susceptible to infection (GimenezIbanez et al. 2009; Zipfel et al. 2004). However, although patterntriggered immunity (PTI) is hypothesized to play a central role in defense against many types of pathogens (Zhang and Zhou 2010), the exact defense mechanisms that limit pathogen growth are poorly defined, in large part due to the complexity of cellular responses involved.

The importance of PTI as a plant defense mechanism is underscored by evidence that many diverse pathogens have evolved mechanisms to suppress the establishment of PTImediated defenses (Toruño et al. 2016). In this regard, $P$. syringae relies on a type III secretion system (T3SS) to suppress PTI (Büttner and He 2009). P. syringae delivers proteins termed effectors into host cells, and many of these effectors are known to interfere directly with activation of PRRs or with components of downstream signaling pathways (Abramovitch et al. 2006). However, T3SS-encoding genes are not constitutively expressed, most likely due to fitness costs associated with producing the many proteins involved (Tang et al. 2006). As a result, $P$. syringae must recognize the host environment at the 
start of infection and rapidly respond by expressing its T3SSencoding genes. Initial studies of in-vitro conditions mimicking the leaf apoplast environment-namely, the lack of complex $\mathrm{N}$ and $\mathrm{C}$ sources, the presence of simple sugars such as fructose or sucrose, and slightly acidic $\mathrm{pH}$ - concluded that these general features of the host environment are necessary and sufficient for T3SS deployment (Huynh et al. 1989; Rahme et al. 1991; Salmeron and Staskawicz 1993; Tang et al. 2006). More recent work with the model strain $P$. syringae DC3000 revealed that specific organic acids and amino acids exuded by plants, including citric acid and malic acid, are potent inducers of T3SS gene expression (Anderson et al. 2014). The importance of these metabolites in regulating disease outcomes was established by studies of Arabidopsis mapk phosphatase 1 ( $\mathrm{mkpl}$ ), a loss-of-function mutant that exudes decreased amounts of these metabolites (Anderson et al. 2014). As a result, $m k p 1$ plants are more resistant to DC3000 infection, a phenotype that could be suppressed by exogenous application of the bioactive metabolites during infection. In addition, $m k p l$ plants also showed enhanced molecular responses to PAMPs (Anderson et al. 2011), suggesting that decreased release of the bioactive metabolites from this mutant plant may be a consequence of a heightened defense response.

Pretreatment of leaf tissue with purified PAMPs interferes with type III effector delivery by $P$. syringae during subsequent infection (Crabill et al. 2010; Oh et al. 2010). Multiple lines of evidence indicate that the underlying cause of this phenotype may be PAMP-dependent changes in the apoplast environment. First, exogenous addition of T3SS-inducing metabolites to PAMP-elicited seedlings allowed DC3000 to overcome both the PAMP-induced block in effector delivery and inhibition of bacterial growth (Anderson et al. 2014). These data suggest that loss of virulence-inducing signals, rather than increased physical barriers per se (e.g., cell-wall defenses), are responsible for decreased effector delivery. Second, recent transcriptomic analyses concluded that T3SS-associated genes are repressed in DC3000 bacteria isolated from PAMP-treated leaf tissue (Lovelace et al. 2018; Nobori et al. 2018). However, whether or not this phenotype is due to decreased levels of T3SS-inducing metabolites, increased levels of T3SS inhibitory compounds that may be present in PAMP-treated tissues, or more general features of the defense-elicited leaf environment was not addressed.

Metabolite-mediated signaling events that occur between $P$. syringae and plant cells during leaf infection are inherently

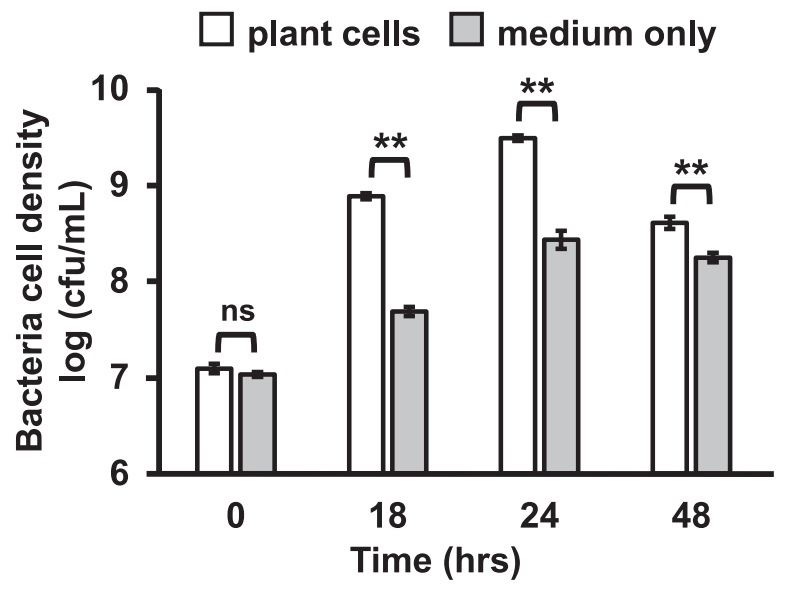

Fig. 1. DC3000 grows to high levels in the presence of plant suspension cells. Arabidopsis T87 suspension cells or medium-only control cultures were infected with Pseudomonas syringae DC3000 (optical density at 600 $\mathrm{nm}=0.01$, approximately $1 \times 10^{7} \mathrm{CFU} / \mathrm{ml}$ ). Bacteria in infected cultures were enumerated by serial dilution plating at the timepoints indicated. Graphs show means \pm standard deviation, $n=3$. Two asterisks $(* *)$ indicate $P<0.01$, based on $t$ test; ns $=$ no significant difference. Results are representative of at least three independent experiments. challenging to study, due to difficulties in extracting bacteria from the apoplast as well as variation in infection and host defenses that occur across uniformly inoculated tissue. Furthermore, metabolite concentrations can change rapidly in planta and during their extraction from leaf tissue. To overcome these challenges, we developed a coculture infection protocol for Arabidopsis suspension cells and $P$. syringae that facilitates rapid and direct analysis of metabolite exchange between host and pathogen. Plant cell suspension cultures are frequently used to investigate plant cell responses to PAMPs, in large part because their homogeneity allows for synchronous molecular responses to exogenously added elicitors. Furthermore, many PAMP-induced cellular responses that occur in leaf tissue also occur in suspension cell cultures, including the production of reactive oxygen species, nitric oxide, extracellular alkalization, callose deposition, and altered defense gene expression (Apostol et al. 1989; Cecchini et al. 2009; Mathieu et al. 1991; Moroz et al. 2017; Navarro et al. 2004; O'Brien et al. 2012; Zeidler et al. 2004), allowing for investigation of these defenserelated processes in a more tractable system. Because of these beneficial features, suspension cell systems have been used for transcriptomics, proteomics and metabolomics studies of PAMP-induced plant cell responses (Benschop et al. 2007; Kaffarnik et al. 2009; Navarro et al. 2004; Peck et al. 2001; Schenke et al. 2011). However, the effects of PAMP treatment on bacterial growth and virulence gene expression in coculture have not been reported.

Here, we demonstrate that growth of $P$. syringae pv. tomato DC3000 is stimulated by the presence of Arabidopsis suspension cells and that enhanced growth requires a functional T3SS, indicating that effectors actively manipulate plant suspension cells to benefit bacterial growth. Similar to effects observed in intact leaf tissue, pretreatment of the Arabidopsis cell cultures with PAMPs effectively limited both the expression of T3SS-associated genes in DC3000 and growth of DC3000 in coculture. Using both metabolomic and biochemical approaches, we demonstrate that PAMP-treated plant cells exude decreased amounts of several organic acids, including the T3SS-inducing metabolite citric acid, and that exogenous application of citric acid can suppress PAMP-mediated inhibition of DC3000 growth in coculture. The coculture protocol described herein provides a valuable method for studying metabolite exchange between plant cells and $P$. syringae during infection as well as possible mechanisms of bacterial growth inhibition by PTI.

\section{RESULTS}

\section{Arabidopsis suspension cells stimulate the growth of $P$. syringae pv. tomato DC3000 in culture.}

As a first step to developing our coculture infection protocol, we infected Arabidopsis T87 suspension cells with $P$. syringae pv. tomato DC3000 and measured bacterial growth over a 48-h time period. At both 18 and $24 \mathrm{~h}$ postinoculation (hpi), we observed a nearly 100 -fold increase in bacteria in the presence of plant cells, and this amount was over 10 times higher than growth of DC3000 in a medium-only control culture (Fig. 1). At $48 \mathrm{hpi}$, the overall population of DC3000 declined in the infected T87 cultures. However, the amount of bacteria was still significantly higher than in the medium-only control culture at this later timepoint (Fig. 1). These results demonstrate that growth of DC3000 is stimulated when cocultured with Arabidopsis suspension cells.

\section{PAMP pretreatment of Arabidopsis suspension cells limits} the growth of $P$. syringae pv. tomato DC3000.

Treatment of plant suspension cells with purified PAMPs elicits molecular responses associated with defense, including 
production of reactive oxygen species, MAPK activation, and altered expression of defense-associated genes (Navarro et al. 2004; Nühse et al. 2000). To assess if PAMP-induced responses of plant suspension cells also alter $P$. syringae growth, we treated T87 plant cells with $1 \mu \mathrm{M}$ of the PAMP elf26 (Kunze et al. 2004) or a mock control for $6 \mathrm{~h}$, then, infected the plant cultures with DC3000. As shown in Figure 2, we observed a significant inhibition of bacterial growth in elf26-treated cultures relative to mock-treated control cultures after $24 \mathrm{~h}$. However, inhibition of growth in elf26-treated cultures was transient, with DC3000 growing to levels observed in mocktreated cultures at 48 hpi (Fig. 2), indicating that DC3000 can overcome the inhibitory effect caused by pretreatment of the plant cells with elf26. No significant difference in bacterial growth was observed between medium-only control cultures supplemented with or without elf26, demonstrating that elf 26 peptide by itself does not inhibit bacterial growth (Fig. 2). We performed a timecourse analysis of PAMP-dependent effects on DC3000 growth and found that $2 \mathrm{~h}$ of elf 26 treatment was sufficient to significantly limit bacterial growth, with increased inhibition occurring with a 6-h pretreatment (Supplementary Fig. S1). Interestingly, DC3000 grew to significantly higher levels in cultures mock-treated for $6 \mathrm{~h}$ compared with $2 \mathrm{~h}$, suggesting that longer incubation times of plant cells in fresh media promotes higher levels of bacterial growth. Treatment of T87 cells with the flagellin-derived PAMP flg22 (Felix et al. 1999) also inhibited DC3000 growth, indicating the observed inhibition of bacterial growth is not elicitor-specific (Supplementary Fig. S2). Together, these results demonstrate that PAMP-induced plant suspension cells can effectively limit the growth of DC3000.

\section{A functional T3SS but not coronatine is required for maximal growth of DC3000 cultured with Arabidopsis suspension cells.}

DC3000 relies on multiple virulence factors including type III effectors and the phytotoxin coronatine to invade and colonize leaf tissue (Xin and He 2013). To test if either the T3SS or coronatine is required for growth of DC3000 in our coculture system, we infected T87 cells with wild-type DC3000, $\Delta h r c C$, or $\Delta c m a A \Delta c f a 6$ mutant strains that are unable to deliver effectors or produce coronatine, respectively. Dilution plating of

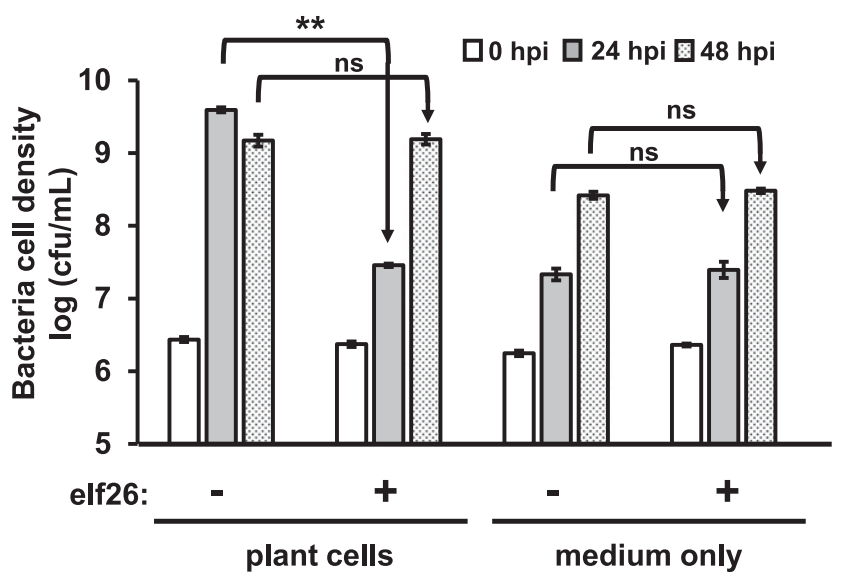

Fig. 2. Pathogen-associated molecular pattern pretreatment of Arabidopsis suspension cells inhibits DC3000 growth in culture. Arabidopsis T87 cells were treated with $1 \mu \mathrm{M}$ elf 26 or a mock control for $6 \mathrm{~h}$, then, were infected with DC3000 (optical density at $600 \mathrm{~nm}=0.01$ ). Bacteria in infected cultures were enumerated by serial dilution plating at the timepoints indicated. Graphs show means \pm standard deviation, $n=3$. Two asterisks $(* *)$ indicate $P<0.01$, based on Student's $t$ test; ns = no significant difference. Results are representative of at least three independent experiments. bacteria at $24 \mathrm{hpi}$ revealed that growth of $\Delta h r c C$ was $>10$-fold lower than wild-type bacteria in the presence of plant cells (Fig. $3 \mathrm{~A})$. No decrease in growth of this mutant was observed in medium-only control cultures (data not shown), indicating that the growth defect of this strain is only evident in the presence of plant cells. In contrast to the T3SS-deficient strain, no significant decrease in growth was observed with the $\Delta c m a A \Delta c f a 6$ strain relative to the wild type at any timepoint tested (Fig. 3A). Overall, these data indicate that a functional T3SS but not coronatine is required for maximal growth of DC3000 in the presence of plant cells. We also tested if type III secretion contributes to DC3000 growth in the presence of PTI-elicited plant cells. We pretreated T87 cells with elf 26 and measured the growth of DC3000 wild type, $\Delta h r c C$, and $\Delta c m a A \Delta c f a 6$ strains in culture with the PAMP-elicited plant cells. At $24 \mathrm{hpi}$, the growth of all strains was significantly inhibited (Fig. 3A). However, the growth level of the $\Delta h r c C$ mutant was even lower than that of the wild type and the $\Delta c m a A \Delta c f a 6$ mutant. More importantly, at $48 \mathrm{hpi}$, the $\Delta h r c C$ mutant was unable to grow to the same levels as wild-type or $\Delta c m a A \Delta c f a 6$ bacteria in the elf26-treated plant cultures (Fig. 3A). Together, these results indicate that a functional T3SS is required for DC3000 to overcome PAMP-induced inhibition of bacterial growth in coculture.

In our experiments we observed that plant suspension cells became visibly darker in color $24 \mathrm{~h}$ after elf 26 treatment (Fig. 3B). Cultures infected with wild-type DC3000 or the
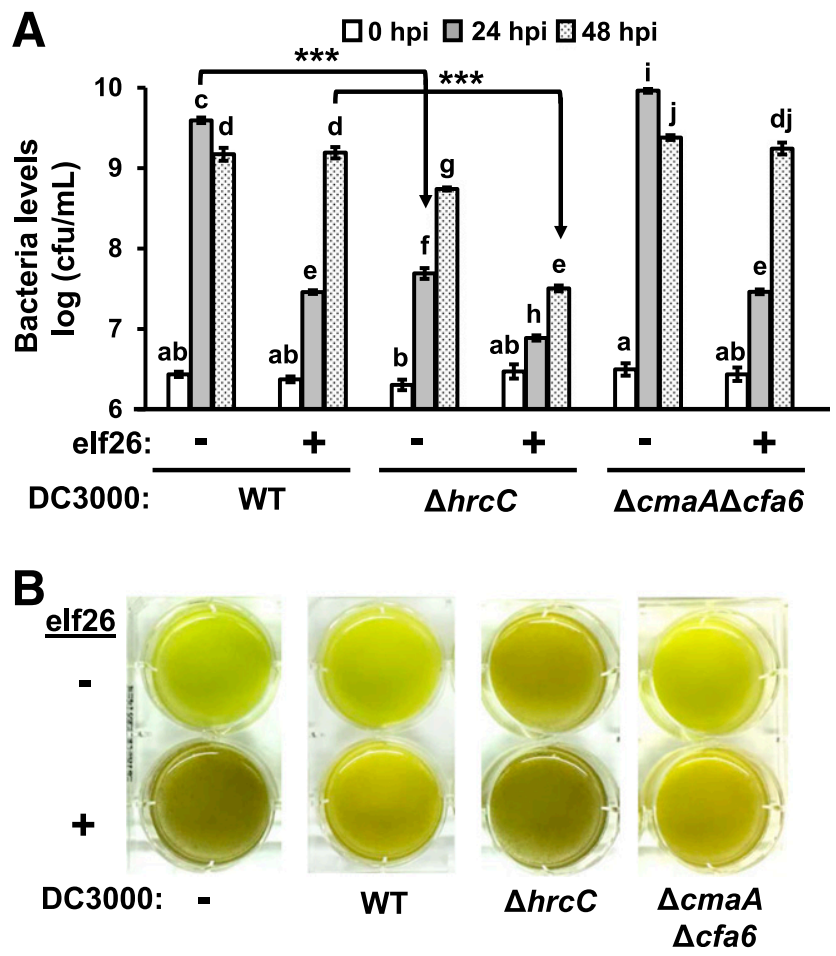

Fig. 3. Type III secretion but not coronatine is required for maximal growth of DC3000 in coculture with plant suspension cells. Arabidopsis T87 cells were treated with $1 \mu \mathrm{M}$ elf 26 or a mock control for $6 \mathrm{~h}$, then, were infected with DC3000, $\Delta h r c C$, or $\Delta c m a A \Delta c f a 6$ strains (optical density at $600 \mathrm{~nm}=$ 0.01 ) as indicated. A, Bacteria in infected cultures were enumerated by serial dilution plating at the timepoints indicated. Graphs show means \pm standard deviation, $n=3$. Letters indicate statistically significant groupings based on analysis of variance and pairwise $t$ tests with Tukey's highly significant difference at $95 \%$ confidence level. Brackets highlight two specific comparisons addressed in text. Three asterisks (***) indicate $P<0.001$. B, Plant suspension cell cultures at $24 \mathrm{~h}$ postinoculation shows color changes that correlate with plant defense and type III secretion systemdependent bacterial growth. Results are representative of at least three independent experiments. 
$\Delta c m a A \Delta c f a 6$ mutant were not as dark as the uninfected PAMPtreated plant cells, whereas the color of cultures infected with the $\Delta h r c C$ mutant was similar to uninfected PAMP-treated cultures (Fig. 3B). These observations are consistent with the increased growth of wild-type DC3000 or $\Delta c m a A \Delta c f a 6$ mutant in the presence of PAMP-treated plant cells compared with the $\Delta h r c C$ mutant (Fig. 3A) and suggest that, in addition to suppressing PAMP-induced inhibition of bacterial growth, effectors may actively suppress PAMP-induced accumulation of chemical compounds that produce this color change.

T3SS gene expression is lower in DC3000 cocultured with PAMP-treated Arabidopsis cells.

Based on our observation that a functional T3SS is required for DC3000 to overcome PAMP-induced inhibition of bacterial growth (Fig. 3A), we hypothesized that reduced growth of wildtype DC3000 in PAMP-treated plant cell cultures is due to an inability of the bacteria to effectively deploy their T3SS. To investigate this possibility, we infected mock- and elf26-treated T87 cells with DC3000 carrying a transcriptional reporter consisting of the promoter of T3SS regulator $h r p L$ fused to a promoterless $g f p$. We collected bacterial cells from the infected

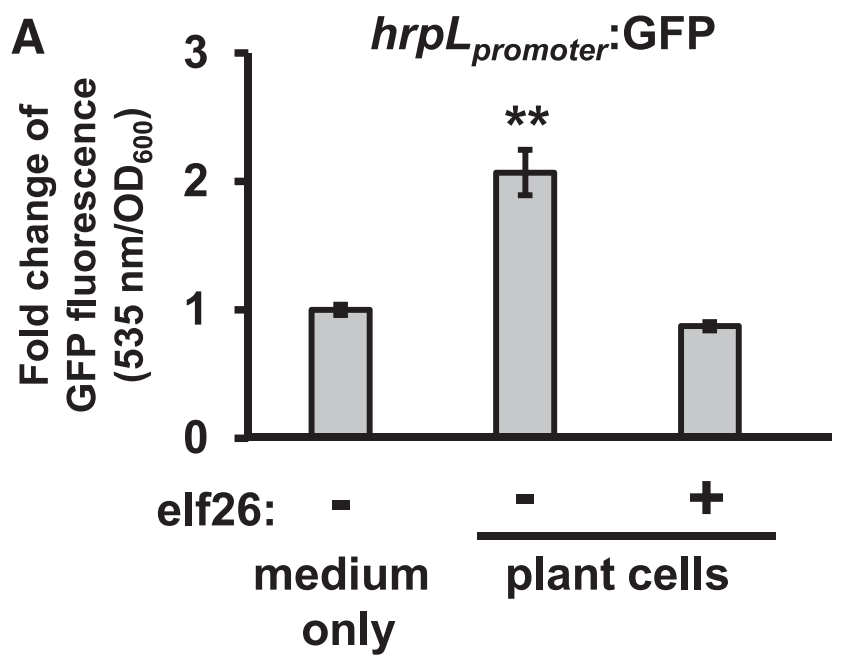

B

\section{a-AvrPto}

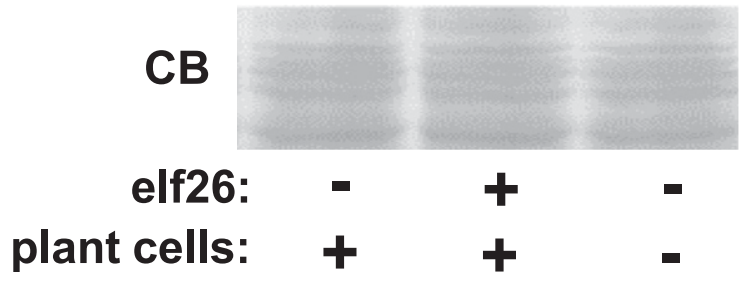

Fig. 4. Expression of type III secretion system effectors is repressed in DC3000 cocultured with pathogen-associated molecular pattern-treated plant suspension cells. Arabidopsis T87 cells were treated with $1 \mu \mathrm{M}$ elf26 or a mock control, then, were infected with DC3000 (optical density at 600 $\mathrm{nm}=0.1$ ) carrying a $h r p L_{\text {promoter }}: g f p$ reporter for $4 \mathrm{~h}$. $\mathbf{A}$, Green fluorescent protein (GFP) fluorescence from DC3000 cultures under different conditions. Graphs show fold change \pm standard deviation $(n=3)$ values of GFP fluorescence relative to medium-only culture. Two asterisks (**) indicate $P<0.01$ based on $t$ test. B, Immunoblot analysis of type III effector AvrPto abundance in cultured bacteria. Upper, chemiluminescent signal from blot probed with anti-AvrPto ( $\alpha$-AvrPto) antibodies; lower, Coomassie blue (CB) staining of blot as a loading control. Data are representative of four independent experiments. cultures at $4 \mathrm{hpi}$ and measured the levels of green fluorescent protein (GFP)-dependent fluorescence. As shown in Figure 4A, hrpL expression was significantly higher in DC3000 cultured in the presence of plant cells compared with medium alone. In contrast, expression of $h r p L$ was significantly lower in DC3000 cultured with elf26-treated plant cells compared with bacteria cocultured with mock-treated plant cells (Fig. 4A). No differences were observed in the number of bacteria present in mockand elf26-treated cultures at 4 hpi (data not shown). Similar results were observed with a DC3000 strain containing a transcriptional reporter plasmid consisting of the promoter of T3SS effector avrRpml fused with a promoterless $g f p$ (Supplementary Fig. S3). We confirmed decreased expression of the T3SS regulon by immunoblot detection of T3SS effector AvrPto in protein extracts prepared from cocultured bacteria (Fig. 4B). Together, these data indicate that the presence of plant cells induces the expression of T3SS-encoding genes in DC3000 and support our hypothesis that this increase in gene expression is inhibited when DC3000 is cocultured with PAMP-treated plant cells.

\section{Cell-free exudates prepared from PAMP-treated}

Arabidopsis cells inhibit T3SS gene expression.

We next examined if soluble factors released from T87 cells act in trans to regulate T3SS gene expression and if these factors are altered in PAMP-treated cultures. T87 cells were first mock- or elf26-treated for $6 \mathrm{~h}$, then, exudates prepared by incubating the pretreated cells in fresh medium for $1 \mathrm{~h}$. After removing plant cells, we then incubated these cell-free exudates with DC3000 hrpL $L_{\text {promoter: }}: g f p$ or $a v r R p m l_{\text {promoter: }}$ :gfp reporter strains. Consistent with our coculture expression data, exudates from mock-treated cells induced T3SS gene expression relative to medium only, and this bioactivity was significantly reduced in exudates from elf26-treated cells (Fig. 5A and B). No difference in bacterial growth was observed with DC3000 cultured in these cell-free exudates at the 4-h timepoint used for GFP measurements (Fig. 5C). However, at later timepoints, a decrease in bacterial growth was apparent in exudate from elf26treated cultures (Fig. 5C). No difference in the $\mathrm{pH}$ of these exudate samples was measured (Fig. 5D). Together, these data indicate that $\mathrm{T} 87$ cells release soluble signals that induce expression of T3SS-associated genes in DC3000 and that these signals are either not present or inhibited in exudates prepared from PAMP-treated cells. Furthermore, exudates from elf26treated plant cells support lower levels of DC3000 growth.

\section{Metabolomic analysis of exudates}

from PAMP-treated Arabidopsis suspension cells.

To investigate the molecular nature of T3SS inhibition by plant suspension cells, we performed a metabolomic analysis of exudates collected from mock- and elf26-treated cultures. T87 cells were first mock- or elf26-treated for $6 \mathrm{~h}$, then, exudates were prepared by incubating the pretreated cells in fresh media for $1 \mathrm{~h}(\mathrm{~T}=6$ mock and $\mathrm{T}=6$ elf 26$)$. These exudates represent the metabolic profile encountered by $P$. syringae within the first hour of our infection protocol. We also prepared exudates from mock-treated cells with no pretreatment period ( $\mathrm{T}=0$ mock) to assess metabolite accumulation patterns based on length of incubation in fresh medium. Gas chromatography-mass spectrometry (GC-MS) analysis of cell culture medium and seven biological replicates of exudates collected in four independent experiments identified a total of 317 spectral features, 69 of which could be assigned to known compounds (Supplementary Table S1). Among all 317 identified features, 78 were significantly different in abundance between at least two of the four treatment conditions examined (analysis of variance [ANOVA], $q$ value < 0.05) (Fig. 6A; Supplementary Table S2). Hierarchical clustering of these 78 features based on accumulation patterns 
revealed four major groups (Fig. 6A, labeled I to IV), with a majority of all features (group II) showing increased accumulation from medium to plant exudate ( $\mathrm{T}=0$ mock and $\mathrm{T}=6$ mock) samples, and lower levels in $\mathrm{T}=6$ elf 26 samples relative to $\mathrm{T}=6$ mock samples. Interestingly, several organic acids previously identified as T3SS-inducing signals, specifically citric acid, fumaric acid, and malic acid, are included in group II. A smaller subset of metabolites increased in abundance in $\mathrm{T}=6$ elf 26 exudates relative to the other three treatment conditions (group III) and includes sugars glucose, fructose, raffinose, xylose, lyxose, and 1-methylgalactose, among others. Two features (phosphate and 111791) make up group IV and show a pattern of depletion in the presence of plant cells.

We focused our analysis on $\mathrm{T}=6$ exudates and identified 13 features that differentially accumulate between mock and elf 26 treatments (paired $t$ tests, Tukey's highly significant difference [HSD], $P<0.05$ ) (Fig. 6B; Supplementary Table S3). Seven of these features were matched to known compounds including citric acid, glucose, glycerol-3-galactose, and $\gamma$-aminobutyric acid (GABA) (Fig. 6C). We selected citric acid for follow-up experiments and, using an enzyme-linked assay, independently confirmed the differential accumulation of this metabolite in exudates (Fig. 6D). We measured an average concentration of $82 \mu \mathrm{M}$ for citric acid in $\mathrm{T}=6$ mock-treated exudates (Fig. 6D), an amount sufficient to account for bioactivity of exudates based on in-vitro measurements of the T3SS-inducing activity of this metabolite (Anderson et al. 2014). The concentration of citric acid was about six times lower in the PAMP-treated plant exudates $(T=6$ elf26) than that of the mock samples $(T=6$ mock). We also measured the abundance of malic acid by enzyme-linked assay and detected a significant reduction of this metabolite in $\mathrm{T}=6$ elf 26 samples (Fig. 6D). Together, these data indicate that PAMP-treatment results in significant changes to the exometabolome of T87 suspension cells, with metabolites both increasing (e.g., glucose) and decreasing (e.g., citric acid) in abundance.

\section{Exogenous addition of citric acid suppresses PAMP-induced inhibition of T3SS gene expression and bacterial growth by $\mathrm{T} 87$ suspension cells.}

We reasoned that decreased abundance of citric acid or malic acid in exudates from elf26-treated cells may be responsible for the decreased bacterial growth. To test this possibility, we added citric acid to the plant cell cultures at the start of infection by DC3000 and assessed bacterial growth in these treated cultures. The addition of $100 \mu \mathrm{M}$ citric acid, a concentration similar to levels in $T=6$ mock exudates (Fig. 6D), significantly increase growth of DC3000 in elf26-treated cultures (Fig. 7A). We also included DC3000 $\Delta h r c C$ in these experiments to test if T3SS is required for the observed citric acid-induced increase in growth and found that this mutant was substantially compromised in this response (only 1.6-fold increase for $\Delta h r c C$ compared with 3.8-fold increase for wild-type bacteria [Fig. 7A, inset]). Nevertheless, $\Delta h r c C$ growth in elf26treated cultures was significantly increased by citric acid in two of three experiments (Fig. 7A; Supplementary Fig. S4), indicating that T3SS-independent responses of DC3000 to this metabolite or effects of citric acid on plant cells may be responsible for the slight increase in growth of this mutant. We note that $100 \mu \mathrm{M}$ citric acid had no effect on bacterial growth in the absence of plant cells under our coculture conditions (Supplementary Fig. S5). Therefore, the observed citric acidinduced growth (both T3SS-dependent and -independent) only occurred in the presence of plant cells.

We also assessed if altering the amount of citric acid added during infection would alter bacterial growth; however, no
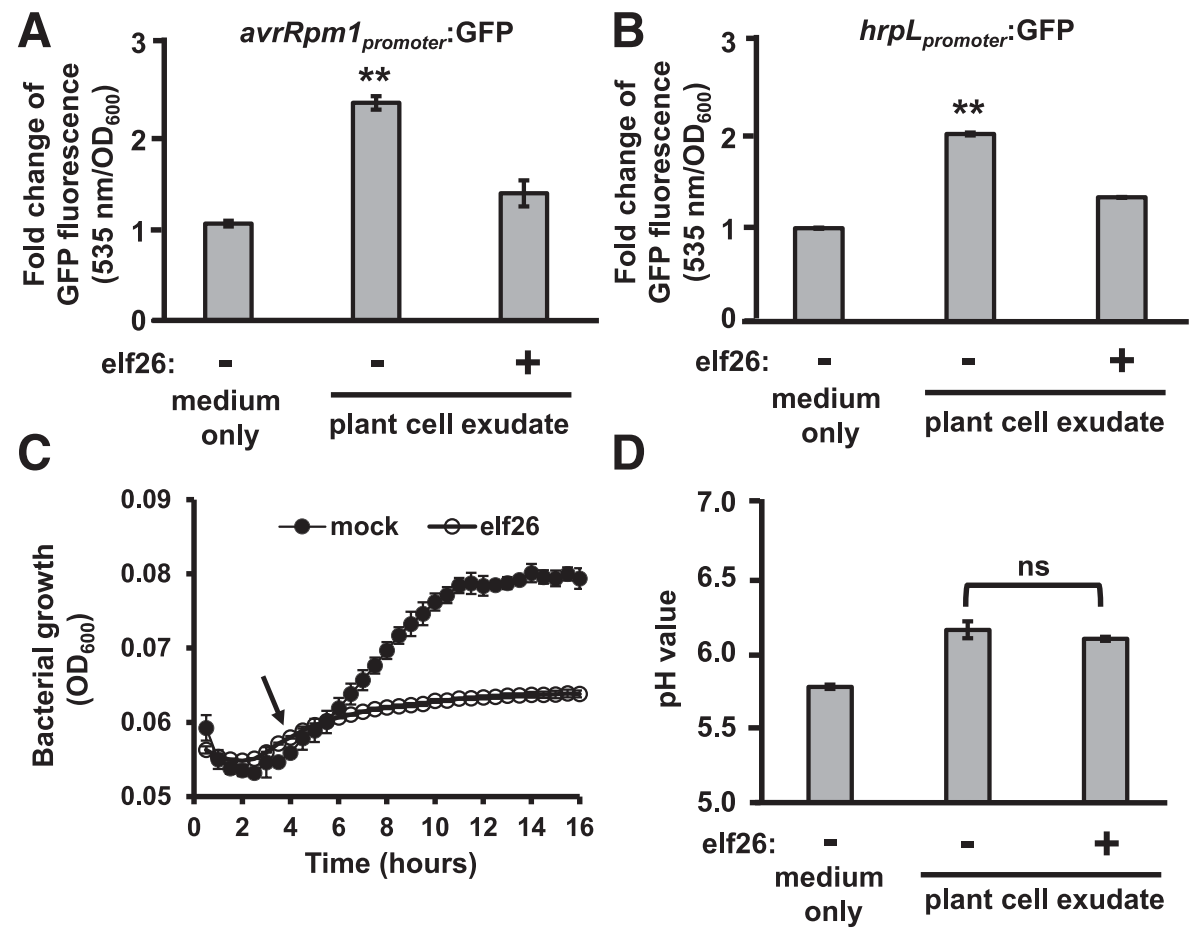

Fig. 5. Soluble signals released from Arabidopsis suspension cells regulate type III secretion system gene expression in DC3000. T87 cells were treated with $1 \mu \mathrm{M}$ elf 26 or dimethyl sulfoxide (mock) for $6 \mathrm{~h}$, and exudates were prepared from these mock- or elf26-treated cultures by incubating cells in fresh medium for $1 \mathrm{~h}$. These cell-free exudates were then incubated with A, DC3000 avrRpm $1_{\text {promoter }}: g f p$ or B, DC 3000 hrpL $L_{\text {promoter: }} g f p$ reporter strains for 4 h. C, Growth of DC3000 avrRpm $1_{\text {promoter: }}$ fp reporter strain in the exudates from mock- or elf26-treated plant suspension cells. Arrow indicates the timepoint shown in A. $\mathbf{D}, \mathrm{pH}$ of exudates prepared from mock- and elf26-treated suspension cells, as described above. Graphs show means \pm standard deviation $(n=3)$ of plant suspension cultures or medium samples. Two asterisks $(* *)$ indicate is $P<0.01$ based on $t$ test; ns $=$ no significant difference. Data in all panels are representative of three independent experiments. 
significant difference in bacterial growth was observed between 50 and $100 \mu \mathrm{M}$ citric acid treatments, suggesting citric acidinduced effects saturate at a concentration of $50 \mu \mathrm{M}$. These data indicate that other unknown factors may contribute to the observed PAMP-dependent growth inhibition and cannot be overcome by increased citric acid alone.

We next tested the effect of citric acid on T3SS deployment by DC3000 and found that addition of $100 \mu \mathrm{M}$ citric acid increased AvrPto abundance in bacteria cocultured with elf26treated T87 cells (Fig. 7B). Similarly, citric acid increased AvrPto levels in DC3000 incubated with exudates prepared from elf26-treated plant cells (Fig. 7C). We also tested if exogenous malic acid, identified in our GC-MS analysis and an inducer of T3SS gene expression (Anderson et al. 2014), or aspartic acid, also an inducer of T3SS (Anderson et al. 2014), could overcome elf26-dependent inhibition of T3SS gene
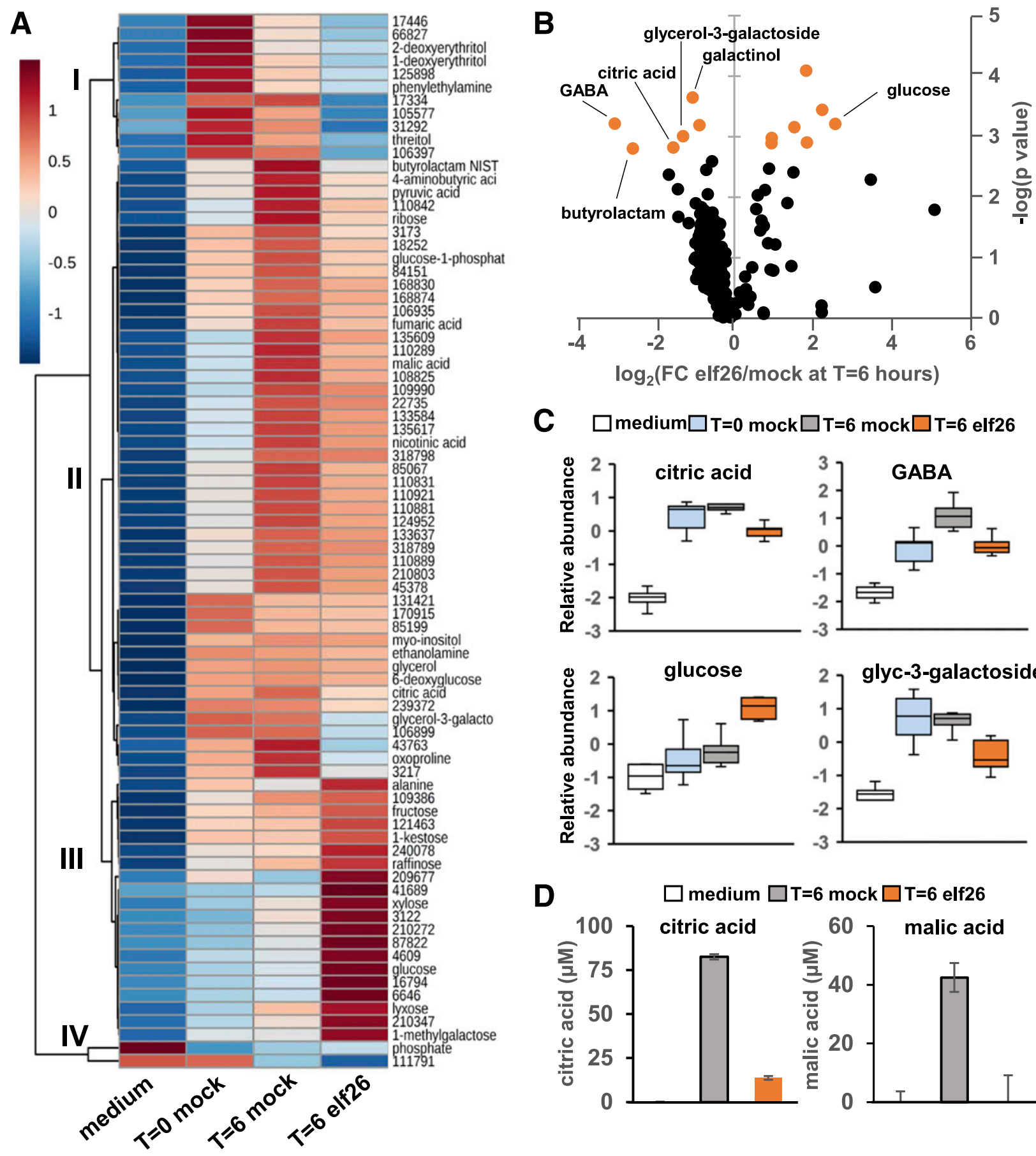

C $\square$ medium $\square \mathrm{T}=0$ mock $\square \mathrm{T}=6$ mock $\square \mathrm{T}=6$ elf26
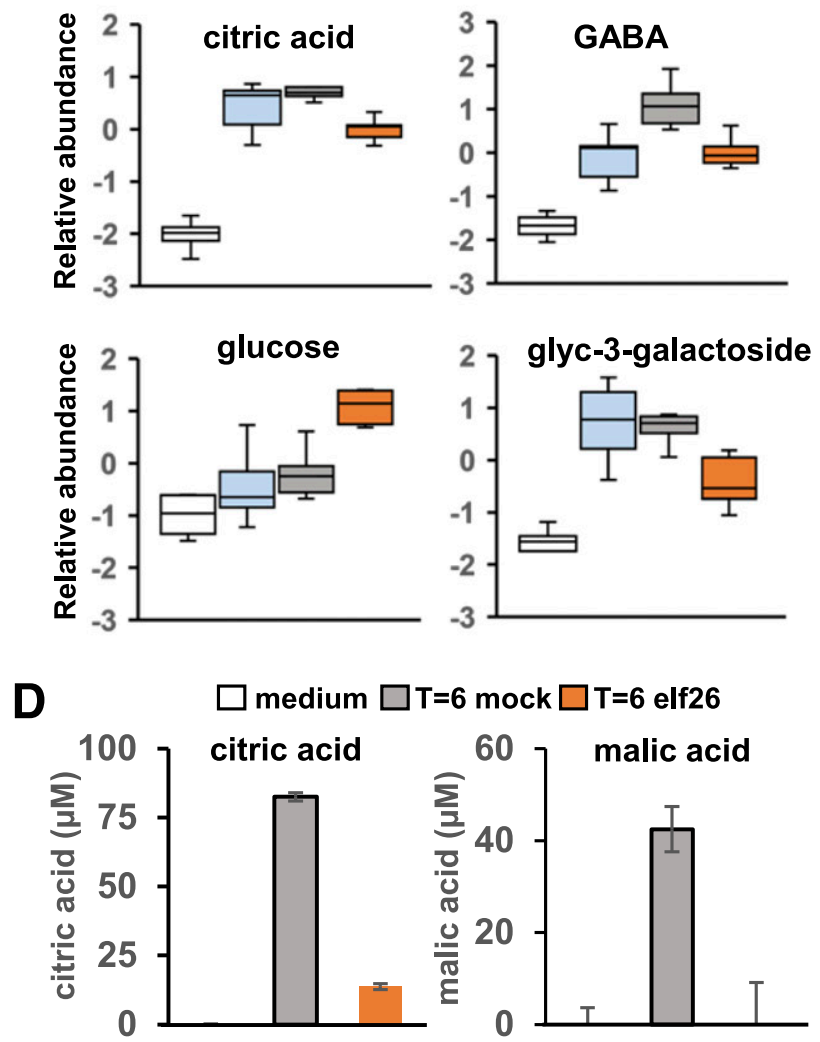

Fig. 6. Pathogen-associated molecular pattern-dependent changes in the exometabolome of Arabidopsis suspension cells. Exudates prepared from T87 cells mock-treated for 0 or $6 \mathrm{~h}$ or treated with $1 \mu \mathrm{M}$ elf 26 for $6 \mathrm{~h}$ were analyzed by gas chromatography-mass spectrometry. A, Heat map of 78 metabolite features that differ in abundance among all treatment conditions based on analysis of variance (ANOVA) $(P<0.05$, Fisher's highly significant difference test). Data were log-transformed and autoscaled prior to ANOVA and groupings were determined by hierarchical clustering. Roman numerals highlight four major groupings with distinct accumulation profiles. $\mathbf{B}$, Volcano plot of metabolite fold change (FC) and corresponding $P$ values between $\mathrm{T}=6 \mathrm{~h}$ elf 26 and $\mathrm{T}=6 \mathrm{~h}$ mock exudates. Highlighted in orange are metabolite features that significantly differ in abundance $(q$ value $<0.05)$, known metabolites are labeled. C, Box and whisker plots of log-transformed and autoscaled peak heights of selected metabolites. D, Citric acid and malic acid levels in exudate samples based on enzymelinked assay. Graphs show means \pm standard deviation, $n=3$. Data are representative of three independent experiments. 
expression and DC3000 growth. Neither metabolite increased AvrPto accumulation to levels observed in response to citric acid or significantly increased DC3000 growth in coculture with elf26-treated T87 cells (Supplementary Fig. S6), although both metabolites significantly increased $h r p L$ expression in infection medium alone to levels similar to or higher than those of citric acid. Together, these data demonstrate that exogenously added citric acid can partially overcome the observed PAMP-dependent decrease in T3SS gene expression and that a functional T3SS is required for citric acid to maximally enhance the growth of DC3000. Also, the ability of exogenously added metabolites to induce T3SS expression in coculture directly correlates with their ability to significantly increase DC3000 growth in the presence of elf26-treated T87 cells.

To confirm that citric acid increases T3SS gene expression in elf26-treated cultures, we measured plant cell death caused by an avirulent DC3000 avrRpt2 strain as a proxy for the amount of effector delivered into plant cells. Using Evan's Blue staining, we found that cell death caused by DC3000 avrRpt2 was

A

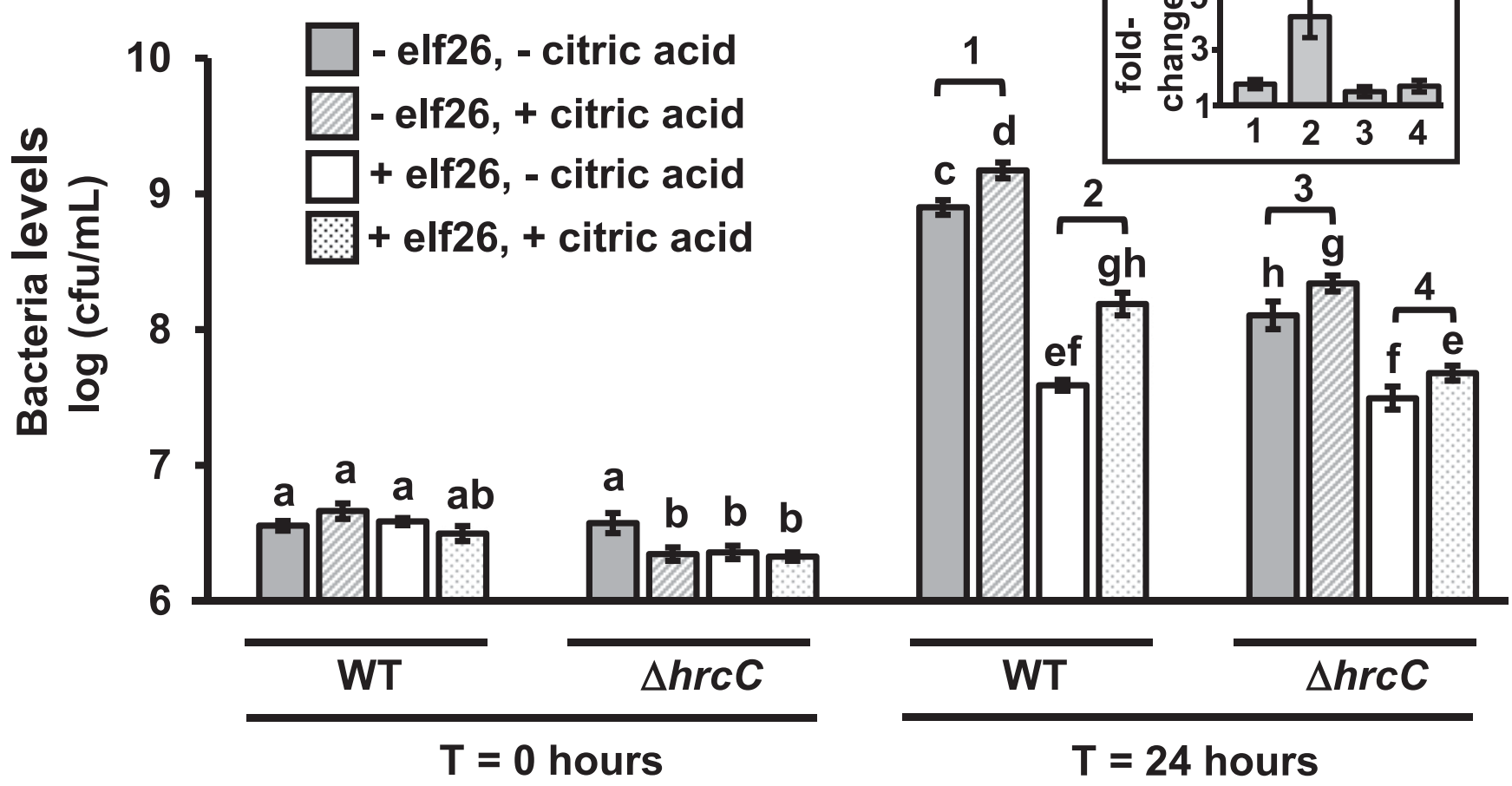

B

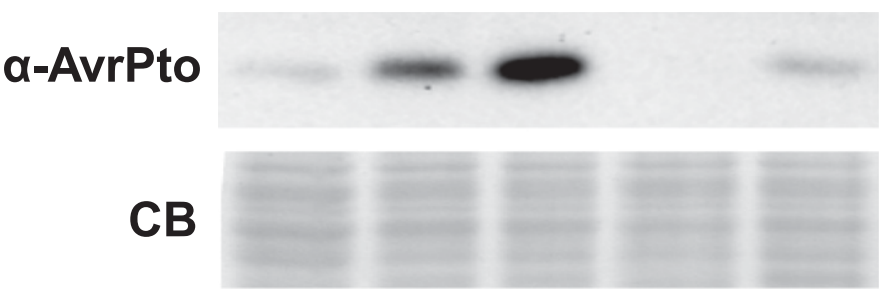

C
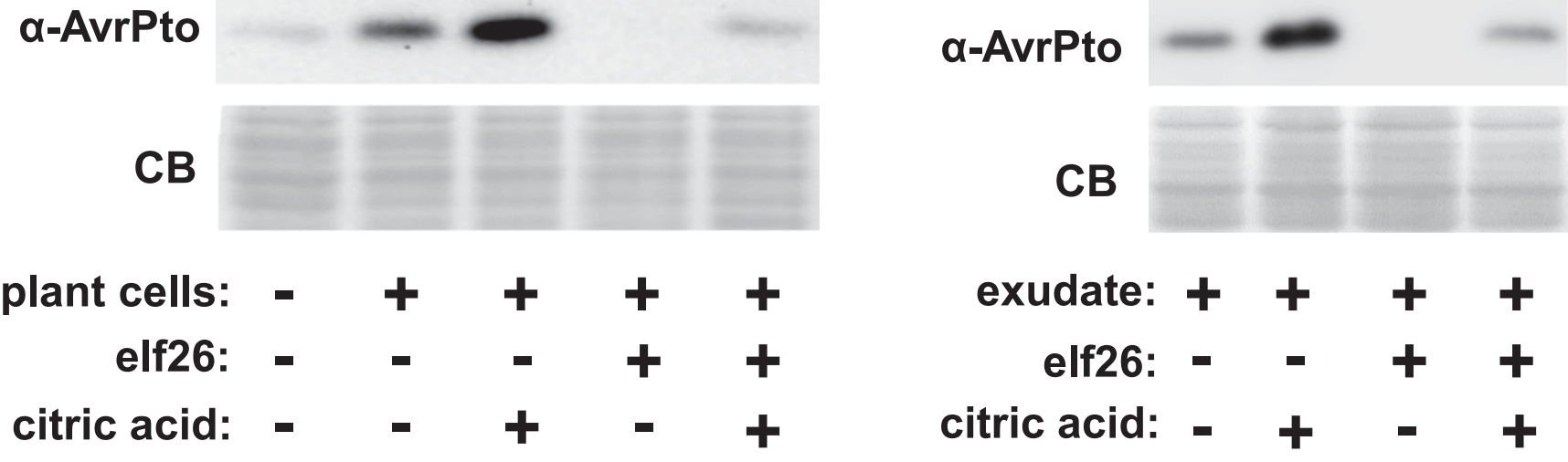

Fig. 7. Exogenous addition of citrate suppresses pathogen-associated molecular pattern-induced inhibition of DC3000 growth and induces expression of the type III secretion system effector in coculture. A, DC3000 or $\Delta h r c C$ (optical density at $600 \mathrm{~nm}\left[\mathrm{OD}_{600}\right]=0.01$ ) were cocultured with T87 cells treated with $1 \mu \mathrm{M}$ elf 26 or dimethyl sulfoxide (mock). Citric acid was added as indicated to a final concentration of $100 \mu \mathrm{M}$. Bacteria were enumerated by serial dilution plating at timepoints indicated. Small letters denote significance groupings based on analysis of variance and pairwise $t$ tests with Tukey's posthoc analysis, $P<$ 0.05. Data are representative of three independent experiments. The inset graph shows mean \pm standard error of the average fold change in bacteria levels between treatment conditions indicated by numbered brackets in graph below, $n=3$. Average fold change values in the inset graph were calculated from all three independent experiments. One asterisk (*) indicates $P<0.05$, based on $t$ test. B and $\mathbf{C}$, Immunoblot analysis of type III effector AvrPto abundance in cultured bacteria. Upper panels show chemiluminescent signal from blot probed with anti-AvrPto antibodies, lower panels show Coomassie blue (CB) staining of blot as a loading control. In B, T87 cells were pretreated with or without elf 26 for $6 \mathrm{~h}$ and then were incubated with $\mathrm{DC} 3000(\mathrm{OD} 600=0.1)$ and $100 \mu \mathrm{M}$ citrate for $6 \mathrm{~h}$ before collecting bacterial cells for immunoblot analysis. In C, Exudates were prepared from T87 cells treated with $1 \mu \mathrm{M}$ elf 26 or mock for $2 \mathrm{~h}$ and then incubated with DC3000 $\left(\mathrm{OD}_{600}=0.1\right)$ in the presence or absence of $100 \mu \mathrm{M}$ citrate. Immunoblot shows AvrPto abundance $2 \mathrm{~h}$ posttreatment. Data are representative of three independent experiments. 
decreased in coculture with elf26-treated cells and that exogenous citric acid significantly increased cell death caused by this strain in elf26-treated cultures (Supplementary Fig. S7). Citric acid treatment did not increase the levels of dead cells in cultures infected with wild-type or $\Delta h r c C$ bacteria, indicating that the increased cell death observed is specific to the avirulent DC3000 avrRpt2 interaction with Col-0 cells. DC3000 also induced lower levels of cell death in mock-treated cultures that was not observed in $\Delta h r c C$-infected or elf26-treated cultures, possibly due to nonspecific cell death caused by high levels of bacteria. We conclude from these data that citric acid increases AvrRpt 2 delivery into elf26-treated T87 cells, leading to increased cell death due to recognition by RPS2. These data provide further support for our conclusion that decreased citric acid contributes to restriction of T3SS gene expression and bacterial growth in PAMP-treated suspension cultures.

\section{DISCUSSION}

The exchange of metabolites between $P$. syringae and plant cells during early stages of infection likely regulates most, if not all, aspects of both pathogen virulence and host defense responses. Metabolites released by plant cells onto the leaf surface or into the apoplast may either directly support or inhibit bacterial growth (Chen et al. 2010), function as signaling cues to induce the expression of virulence-associated genes, or both (Anderson et al. 2014). P. syringae, in turn, produces small molecule toxins and plant hormones that function to suppress host defenses (McClerklin et al. 2018; Xin and He 2013). All these processes likely occur concurrently during infection, resulting in a complexity of metabolite-level interactions that are inherently challenging to study due to difficulties in extracting metabolites from infection sites within intact plant tissue. Therefore, there is a need for simple, tractable experimental systems to identify and quantify metabolites that are exchanged between pathogen and host cells during infection.

\section{Advantages of 'infection in a flask' \\ for investigating the regulation of type III secretion by plant-derived metabolite signals.}

Our goal in developing this coculture protocol was to investigate metabolite exchange between DC3000 and plant cells leading to virulence gene induction and how this signaling process may be perturbed by PAMP-induced defenses. We reasoned that the homogenous and clonal nature of T87 cells as well as the tightly-controlled environmental conditions experienced by both plant and bacterial cells in coculture would serve to minimize the variability in infection timing that likely occurs in intact tissues. Furthermore, the dispersed nature of cells in this system makes it relatively easy to rapidly separate bacterial cells, plant cells, and culture medium, thereby minimizing sample loss and degradation that can occur during metabolite isolation.

Similar cell culture-based approaches to investigating $P$. syringae infection and PAMP-triggered responses have been reported. $P$. syringae DC3000 was previously shown to grow in Arabidopsis suspension cell cultures in a T3SS-dependent manner (Cecchini et al. 2009). In this study, bacteria were incubated in defined T3SS-inducing medium for several hours prior to coculture. Therefore, the ability of the plant cell environment to induce T3SS gene expression was not addressed, nor did this study investigate the effects of PAMP-treated plant cells on bacterial growth. In addition to examining DC3000 growth in coculture, several metabolomics studies of $P$. syringaesuspension cell infections and PAMP-treated suspension cell cultures have been performed. Using Fourier transform infrared spectroscopy, Allwood et al. (2010) reported that DC3000 induced distinct changes in the metabolic fingerprint of Arabidopsis suspension cells compared with changes induced by an effector-compromised DC3000D28E strain, although specific metabolites were not identified. More recent GC-MS and liquid chromatography-MS studies examined PAMP- and DC3000induced changes in the extracellular metabolome of Arabidopsis suspension cells, collectively identifying hundreds of metabolites and documenting differential accumulation patterns (Finnegan et al. 2016; Misra et al. 2016). In designing our coculture experiments, we took a different approach from these previous studies. We first established culture conditions that support high levels of DC3000 growth, demonstrating that enhanced bacterial growth was T3SS-dependent and only occurred in the presence of plant cells. We then used these defined conditions to investigate the effects of PAMP treatment on T3SS gene expression and bacterial growth in coculture and, through our metabolomics analysis, identified a specific metabolite, citric acid, as a key contributor to PAMP-induced effects on bacterial growth. Combining metabolomics and DC3000 infection within the same experimental system allowed us to establish a causal link between observed PAMPinduced inhibition of bacteria and altered levels of a single metabolite. However, our observation that citric acid only partially counteracts PAMP-dependent effects (Fig. 7) indicates that additional metabolic changes likely contribute to PTI observed in coculture. We anticipate that our approach will be valuable for additional metabolomics and biochemical studies to identify these metabolites.

This coculture system may also address gaps in existing knowledge of type III secretion. For instance, relatively little is known about how the secretion apparatus interacts with plant cells to deliver effectors (Büttner and $\mathrm{He} 2009$ ), in part due to the challenge of studying bacteria-plant cell associations within the leaf tissue environment. DC3000 requires a functional T3SS for maximum growth in coculture (Fig. 3) suggesting a close physical association occurs between plant and bacterial cells to facilitate transfer of effectors through the T3SS pilus as well as through the translocon that is likely established in the host cell membrane (Büttner and He 2009). Therefore, our coculture protocol may be useful for quantitative biochemical and direct cell imaging assays (Henry et al. 2017; Park et al. 2017) to assess timing, amount and order of effector delivery into individual host cells, as well as for studying physical associations that occur between the secretion apparatus and plant cells.

Despite these advantages and potential applications, there are several drawbacks that are inherent to this coculture system. First, the amount of water available to $P$. syringae in coculture far exceeds that found in the apoplastic space of leaf tissue. During infection of defense-elicited leaf tissue, DC3000 experience high levels of water stress, indicating that plant defenses may restrict access to water in the apoplast (Wright and Beattie 2004). In this regard, DC3000 effectors AvrE and HopM1 were recently shown to promote an aqueous environment in the apoplast and their combined activities are necessary for maximum growth of DC3000 in leaf tissue during compatible interactions (Xin et al. 2016). In the coculture system, the larger volume of water surrounding the bacteria may alleviate any inhibitory effects of water stress that occurs in planta as well as AvrE/HopM1-mediated promotion of apoplastic water levels, thus potentially altering infection dynamics. Second, few reverse genetic studies of plant suspension cells have been reported to date, and this potentially limits followup studies to discern mechanisms underlying observed phenotypes. However, new gene-editing approaches (Mercx et al. 2016) as well as methods for long-term storage of suspension cell lines (Ogawa et al. 2012) may make these types of studies 
feasible in the future. Finally, although suspension cells are often used to model the apoplast environment, the homogenous nature of the coculture system may not reflect in-planta conditions. For instance, cell type-specific defenses may be lacking as well as microenvironments that influence infection outcomes. Nevertheless, the requirement of T3SS for DC3000 growth in coculture and the ability of PAMP perception to interfere with this growth argue that conditions in this cell system do, in fact, approximate in-planta conditions and that this infection model will be a valuable complement to leaf infection studies.

\section{Arabidopsis suspension cells stimulate the growth of $P$. syringae $\mathrm{DC} 3000$.}

Growth of DC3000 was clearly stimulated when the bacteria were cocultured with T87 cells, yet the exact nutrient source or sources responsible for this plant cell-dependent growth are not known. The medium used for coculture infection contains nutrients necessary for plant cell growth, specifically, sucrose, ammonium nitrate, and potassium nitrate, which could serve as possible carbon and nitrogen sources for bacterial growth. However, this defined medium was suboptimal when compared with levels of growth in the same medium containing plant cells (Fig. 1). This suggests that DC3000 can obtain additional nutrients from T87 cells that promote a faster rate and overall higher level of bacterial growth. Our metabolomics analysis revealed a diverse collection of metabolites, predominantly organic acids and sugars, that are exuded by T87 cells into the culture medium (Fig. 6), and many of these compounds, including citric acid, could potentially be used by DC3000 as energy sources, based on previous Biolog assays (Rico and Preston 2008). However, although exogenous addition of citric acid stimulated DC3000 growth in this system (Fig. 7), it is unlikely that this metabolite was directly responsible for the enhanced plant cell-dependent growth of DC3000, for two reasons. First, the low amount of citric acid used in our assays did not increase bacterial growth in the absence of plant cells as it did in the presence of plant cells (Fig. 7A). Second, citric acid-induced growth in coculture was primarily T3SSdependent (Fig. 7A), suggesting that the effect of this metabolite on DC3000 growth was mostly due to its ability to induce the expression of T3SS-associated genes (Fig. 7B and C). Based on this reasoning, it is likely that metabolites other than citric acid, possibly other organic acids, are necessary to support the increased bacterial growth we observed in coculture. Whether a single metabolite or a collection of metabolites is responsible for the growth-promoting effects of suspension cells will require further studies to measure the absolute abundance and depletion rates of individual metabolites during infection. Alternatively, it may be possible to use auxotrophic mutants compromised in one or both uptake and catabolism of specific metabolites to assess the relative contribution of each metabolite to DC3000 growth.

\section{DC3000 requires a functional T3SS \\ for maximum growth in coculture with plant cells.}

Our data indicate that DC3000 can deliver effectors into individual, isolated plant cells in liquid suspension, and that the activity of these effectors within plant suspension cells contributes to bacterial growth. Possible explanations for this T3SS-dependent bacterial growth are that effectors i) dampen PTI initiated by recognition of endogenous DC3000 PAMPs, thereby allowing the bacteria to avoid plant defenses in culture, ii) promote bacterial growth by increasing nutrient release from plant cells, or iii) have a combination of both defense suppression and nutrient-promoting activities. The first possibility is supported by extensive evidence that many type III effectors function to suppress host defenses (Abramovitch et al. 2006). The second possibility is only weakly supported by evidence in the literature, as, to date, the functions of $P$. syringae effectors have not been directly linked to promoting nutrient release (Macho 2015). Evidence that effectors can directly promote nutrient access comes from studies of Xanthomonas oryzae TAL (transcriptional activator-like) effectors that directly upregulate rice genes encoding SWEET family transporters, resulting in an efflux of sugars into the apoplast that likely promote bacterial growth (Macho 2015). In Arabidopsis, AtSWEET11 and AtSWEET12 genes are induced during DC3000 infection of leaf tissue in a T3SS-dependent manner (Chen et al. 2010). Whether this molecular phenotype is due to direct action of specific effectors or the result of indirect effects of effector-mediated defense suppression is not known. In this regard, it will be interesting to measure whether the rate of metabolite efflux from T87 cells increases during DC3000 infection and, if so, to assess if the observed differences are T3SS-dependent.

\section{PAMP treatment of suspension cells inhibits expression} of T3SS-encoding genes and DC3000 growth in coculture.

Expression of T3SS-associated genes was reduced when DC3000 was incubated in exudates from elf26-treated T87 cells (Fig. 5A and B), indicating that PAMP-elicited plant cells either exude lower amounts of T3SS-inducing metabolites, higher levels of compounds that inhibit T3SS expression, or both. In addition, overall growth of DC3000 was lower in exudates from PAMP-elicited cultures (Fig. 5C), suggesting that changes in one or both growth-promoting and growth-inhibiting compounds also occur. Our metabolomics and biochemical analyses identified 14 metabolites that significantly increased or decreased in exudates from PAMP-treated suspension cells (Fig. 6B, C, and D). Therefore, these metabolites are top candidates for altering both T3SS gene expression and DC3000 growth. Among these metabolites, several organic acids involved in primary metabolism, specifically citric acid, malic acid, and GABA, decreased in abundance in culture exudates following PAMP treatment of T87 cells (Fig. 6B, C, and D), and our follow-up experiments indicate that decreased citric acid is at least partially responsible for decreased T3SS gene expression in coculture (Fig. 7). A model describing the role of citric acid in limiting DC3000 virulence in PAMP-treated cultures is provided in Supplementary Figure S8. Citric acid is present in the apoplast of leaf tissue and functions in the intercellular transport of iron due to its ability to chelate Fe ions (Roschzttardtz et al. 2011). Both citric acid and malic acid were previously found to be decreased in exudates from $m k p l$ mutant plants, suggesting heightened defenses may generally result in decreased exudation of these metabolites (Anderson et al. 2014). In support of this model, a study of the Arabidopsis leaf metabolome during DC3000 infection found that citric acid levels decreased in total leaf tissue extracts following infection by DC3000 hrpA, a T3SS-deficient mutant that cannot mask the perception of its PAMPs (Ward et al. 2010). Additional experiments will be necessary to assess if altered levels of citric acid in coculture are due to changes in transport, biosynthesis, or catabolism of this metabolite.

Growth of DC3000 was inhibited by PAMP-treated T87 cells within the first $24 \mathrm{~h}$ after infection, yet the bacteria were able to overcome this inhibition in a T3SS-dependent manner at later stages of infection (Fig. 2). This transient pattern of growth is markedly different from DC3000 growth in leaf tissue treated with PAMPs prior to infection, in which bacteria are unable to overcome PTI within a typical multiday bacterial growth assay (Zipfel et al. 2004). It is possible that, at later timepoints, suspension cells exhaust the supply of nutrients in the culture 
medium, thus preventing the cells from maintaining an active defense response for longer periods of time. Also, mechanisms of PTI that occur in leaf tissue may be different from those in the suspension cell cultures. Nevertheless, the fact that DC3000 required a functional T3SS to overcome the inhibitory effects of PAMP-treated plant cells suggests that reversion in bacterial growth is an active process that requires type III secretion. Our measurements of T3SS-associated gene expression at early infection timepoints indicate that effector production in bacteria cultured with PAMP-treated cells was reduced to nearly nondetectable levels (Figs. 4 and 7). Therefore, either a low level of effector delivery into elf26-treated cells was sufficient over longer time periods to suppress PTI and enhance bacterial growth or inhibition of T3SS deployment was transient and higher levels of effectors were produced at later timepoints after infection. Future experiments to investigate the transient nature of PTI in this system and molecular responses of plant cells to DC3000 infection may provide valuable insights into how effectors manipulate plant cells to benefit bacterial growth.

It is interesting to note that growth of DC3000 in the presence of PAMP-elicited T87 cells was not reduced below levels of growth in medium only (Fig. 2), suggesting that PAMP-induced effects observed in coculture may be bacteriostatic rather than bactericidal. Our conclusion that decreased citric acid accumulation contributes to decreased DC3000 growth in coculture is consistent with this hypothesis. In leaf tissue, PAMP pretreatment also reduces DC3000 growth (Crabill et al. 2010). However, bacteria are still able to grow significantly higher than inoculum levels in PAMP-treated tissues, suggesting that any bactericidal effects of PTI, if present, are either transient or weakly effective at killing (Crabill et al. 2010). It is also possible that pretreating plant tissues with PAMPs several hours before infection, either in coculture or in leaves, could overlook possible bactericidal effects, such as the extracellular reactive oxygen that are produced rapidly and transiently following PAMP perception.

\section{MATERIALS AND METHODS}

\section{Materials.}

N-terminal acetylated elf26 (Kunze et al. 2004) and flg22 (Felix et al. 1999) peptides were synthesized by Genscript Corp. and were maintained as $10 \mathrm{mM}$ stocks in dimethyl sulfoxide (DMSO) at $-20^{\circ} \mathrm{C}$.

\section{Bacterial strains and growth conditions.}

P. syringae DC3000 $\Delta h r c C$ (Peñaloza-Vázquez et al. 2000), DC3000 $\Delta c m a A \Delta c f a 6$ (Brooks et al. 2004), and DC3000 expressing avrRpt2 from plasmid pV288 were previously described (Kunkel et al. 1993). Bacteria were maintained as $-80^{\circ} \mathrm{C}$ glycerol stocks and were cultured on King's B (KB) medium agar, at room temperature, for 2 days prior to plant cell culture infection.

\section{Transcriptional reporter constructs $h r p L_{\text {promoter }}-g f p$ and avrRpm $1_{\text {promoter }}$ gfp.}

The $h r p L_{\text {promoter }}: g f p$ transcriptional reporter contains the promoter of $h r p L$ fused to a promoterless $g f p$ in vector pPROBE-NT (Miller et al. 2000). To make this construct, a 470-bp DNA fragment was polymerase chain reaction (PCR)amplified from DC3000 genomic DNA using oligonucleotides hrpL-F1 (5'-ATAAAGCTTCACCGCTCGCGACTG-3') and hrpL-R1 (5' -ATAGGTACCCTGATTTAGTGGTGTAC-3'). The resulting PCR fragment was digested with HindIII and $K p n I$ and was ligated into pPROBE-NT. The avrRpml:gfp reporter plasmid was provided by J. Chang and was reported previously (Chang et al. 2005). This construct contains a synthetic operon consisting of avrRpml fused to a C-terminal hemagglutinin tag followed by a gene encoding GFPmut3 (Cormack et al. 1996), with both genes under the control of the native avrRpml promoter in broad host range vector pBBR1MCS-2 (Kovach et al. 1995).

\section{Arabidopsis suspension cell growth conditions.}

Arabidopsis T87 suspension cells derived from the Columbia ecotype (Axelos 1992) were obtained from the Arabidopsis Biological Resource Center and were maintained in a modified NT-1 medium (1× Murashige and Skoog basal salts [Phytotechnology Laboratories], 3\% (wt/vol) sucrose, $1.3 \mathrm{mM}$ $\mathrm{KH}_{2} \mathrm{PO}_{4}, 410 \mu \mathrm{g}$ of 2,4-dichlorophenoxyacetic acid per liter, and $100 \mathrm{mg}$ of myo-inositol per liter, $\mathrm{pH}$ adjusted to 5.8 with $\mathrm{NaOH}$ ), sterilized by filtration through a $0.2-\mu \mathrm{m}$ polyethersulfone membrane. Sterile 125-ml Erlenmeyer flasks containing $40 \mathrm{ml}$ of culture were kept, at $23^{\circ} \mathrm{C}$ and 24-h light, with $130 \mathrm{rpm}$ shaking in a refrigerated orbital platform shaker. Cultures were subcultured weekly by 10 -fold dilution into fresh NT-1 medium. A biosafety cabinet was used to maintain sterility of the plant cell cultures during cell passaging and while preparing cells for infection experiments.

\section{Coculture of $P$. syringae with Arabidopsis suspension cells.}

Nine-day-old T87 cell culture $(40 \mathrm{ml})$ was transferred to a sterile 50-ml conical tube and was washed twice with $25 \mathrm{ml}$ of NT-1 medium. Cells were pelleted between washes by brief centrifugation at $100 \times g$ in a swinging bucket clinical centrifuge. The packed volume of cells after centrifugation was typically 20 to $25 \mathrm{ml}$. After washing, the cells were divided equally into two $125-\mathrm{ml}$ flasks, and the volume in each flask was adjusted to $50 \mathrm{ml}$ with NT-1 medium. Each flask was treated with either $5 \mu \mathrm{l}$ of $10 \mathrm{mM}$ elf 26 (final $1 \mu \mathrm{M}$ elf26), $5 \mu \mathrm{l}$ of $10 \mathrm{mM}$ flg22, or $5 \mu \mathrm{l}$ DMSO mock control, and was placed back in the shaker used for maintaining T87 cultures. After $6 \mathrm{~h}$, the treated cultures were washed twice into $0.2 \mu \mathrm{m}$ filtersterilized infection medium consisting of $0.5 \times$ Murashige and Skoog basal salts (Phytotechnology Laboratories), 1\% sucrose, $\mathrm{pH}$ adjusted to 5.8 with $\mathrm{NaOH}$. Washes were performed in $50-\mathrm{ml}$ conical tubes as described above. After washing, the volume of each culture was adjusted to $90 \mathrm{ml}$, and $9 \mu \mathrm{l}$ of $10 \mathrm{mM}$ elf26 or DMSO control was added to each. Both mockand elf26-treated cultures were buffered by addition of 2-(Nmorpholino)ethanesulfonic acid- $\mathrm{KOH}, \mathrm{pH} 5.8$, to a final concentration of $10 \mathrm{mM}$ and were aliquoted $5 \mathrm{ml}$ per well into sixwell sterile tissue culture plates. To prepare the inoculum for bacterial infections, a pea-sized amount of DC3000 was scraped from a 2-day-old lawn grown on $\mathrm{KB}$ agar and was resuspended in $1 \mathrm{ml}$ of water by vortexing. After two washes with $1 \mathrm{ml}$ of water, the optical density at $600 \mathrm{~nm}\left(\mathrm{OD}_{600}\right)$ of the resuspended solution of bacteria was adjusted to 0.1 or 1.0 , and $50 \mu \mathrm{l}$ was added to each $5-\mathrm{ml}$ aliquot of treated plant cell cultures in the six-well plates (final $\mathrm{OD}_{600}=0.01$ or 0.001 ). At the time of infection, $25 \mu \mathrm{l}$ of $20 \mathrm{mM}$ citric acid or malic acid stocks were added to the 5-ml cultures. After infection, the plates were sealed with micropore tape (3M Corp.) and were incubated at $23^{\circ} \mathrm{C}$, with $130 \mathrm{rpm}$ shaking in a refrigerated orbital platform shaker, with continuous 24-h light. Bacteria levels in culture were enumerated, at times indicated, by serial dilution of the culture liquid and plating on KB agar with appropriate antibiotics. Statistical analyses of bacterial growth were performed in Minitab software using a general linear model for ANOVA and pairwise $t$ test comparisons between treatment conditions with Tukey's posthoc analysis.

\section{Measurements of T3SS gene expression in DC3000.}

T87 cells were PAMP- or mock-treated in NT-1 medium and were washed into infection medium as described above. An 
$\mathrm{OD}_{600}=1.0$ inoculum of DC3000 harboring avrRpm $1_{\text {promoter }}$ : $g f p::$ pBBR1MCS-2 or $h r p L_{\text {promoter }}: g f p::$ PPROBE-NT $(500 \mu \mathrm{l})$ was added to 5-ml aliquots of plant cells in six-well tissue culture plates (final $\mathrm{OD}_{600}=0.1$ ). Infections with DC3000 harboring promoter-less $g f p:$ :pBBR1MCS-2 and $g f p:$ pPROBE-NT plasmids were included as negative controls. At times indicated, the plant cells were allowed to settle and GFP fluorescence of bacteria in suspension was measured using a Tecan Spark $10 \mathrm{M}$ plate reader. Fluorescence values were normalized to $\mathrm{OD}_{600}$ readings and background-subtracted based on fluorescence from cultures with empty vector GFP strains. For immunoblot analysis, $1 \mathrm{ml}$ of infected culture liquid was centrifuged at $16,000 \times g$ for $1 \mathrm{~min}$, and the resulting bacterial pellets were frozen in liquid nitrogen. Protein extraction from bacterial pellets and anti-AvrPto immunoblots were performed as previously described (Anderson et al. 2014). Protein levels in each lane were normalized based on total protein abundance observed by Coomassie blue staining.

\section{Preparation of suspension cell exudates for measuring T3SS-inducing activity and GC-MS analysis.}

T87 cells were treated with $1 \mu \mathrm{M}$ elf 26 or DMSO mock control as described above for infection assays. After $1 \mathrm{~h}$ of incubation in infection medium, the elf26- and mock-treated cultures were centrifuged at $100 \times g$ for $1 \mathrm{~min}$ to pellet the plant cells. The resulting supernatants were $0.2-\mu \mathrm{m}$ filtered to remove debris and $100 \mu \mathrm{l}$ of clarified sample was incubated with $10 \mu \mathrm{l}$ of $\mathrm{OD}_{600}=1.0 \mathrm{DC} 3000$ harboring avrRpml $1_{\text {promoter }}$ : $g f p$ or $h r p L_{\text {promoter }}: g f p$ reporter plasmids. GFP fluorescence from the bacteria was measured in a Tecan Spark 10M plate reader as described above. Exudates for GC-MS analysis were prepared as described above, with the exception that mock- and PAMP-treated plant cells were incubated in a smaller $30-\mathrm{ml}$ volume of infection medium, rather than $90 \mathrm{ml}$, to increase metabolite levels for detection by MS.

\section{GC-MS analysis of plant cell exudates.}

Collected samples were analyzed for primary metabolites by GC-time-of-flight (TOF)-MS at the NIH West Coast Metabolomics Center at the University of California Davis. Exudate samples $(100 \mu \mathrm{l}$ each) were concentrated to dryness in a Centrivap cold-trap vacuum concentrator (Labconco). Sample derivatization, chromatographic parameters, instrument parameters, and data processing methods were as described (Fiehn et al. 2008). Raw data files are deposited in the Metabolomics workbench database as project number PR000692 (doi: 10. 21228/M8769J). Data were normalized by summing peak heights for all positively identified metabolites in each sample. All subsequent data processing and statistical analyses were performed using MetaboAnalyst version 4.0 (Chong et al. 2018). Briefly, normalized peak height values were filtered by interquantile range, were log-transformed, and were autoscaled by mean-centering and dividing by the standard deviation of each variable. Metabolites that significantly differ in abundance between medium only, $\mathrm{T}=0$ mock, $\mathrm{T}=6$ mock, and $\mathrm{T}=6$ elf 26 samples were identified by one-way ANOVA, using an adjusted $P$ value (false discovery rate) cutoff of 0.05 . A heat map showing hierarchical clustering of ANOVA results was generated using Pearson distance measure and average clustering algorithm settings. Metabolites that differ in abundance between $\mathrm{T}=6$ mock and $\mathrm{T}=6$ elf 26 exudates were identified by pairwise $t$ tests with Tukey's HSD posthoc analysis $(P<0.05)$.

\section{Enzyme-linked assays to measure metabolite concentrations.}

Suspension cell exudates were concentrated 10 -fold by lyophilizing overnight and re-dissolving in a smaller volume of water. Citric acid and malic acid amounts were measured in concentrated samples by commercially available enzymelinked assay kits (Megazyme, Inc.).

\section{Plant cell death measurements.}

The viability of plant suspension cells was tested as described previously (Noutoshi et al. 2012) with modifications. Treated suspension cell culture $(250 \mu \mathrm{l})$ was transferred to a single well of a 96-well plate and the supernatant was carefully removed by pipetting. Three replicate wells were prepared for each treatment condition. The cells in each well were stained in $100 \mu \mathrm{l}$ of Evans blue solution $(5 \%)$ for $10 \mathrm{~min}$, and then, thoroughly washed with sterile deionized water until visible stain was not observed in the wash. The amount of Evans blue stain in the dead cells was determined by resuspending the cells in $250 \mu$ l of destaining solution ( $1 \%$ sodium dodecyl sulfate and $50 \%$ methanol). After $5 \mathrm{~min}$ of incubation, $100 \mu \mathrm{l}$ of the resulting supernatant was collected and the absorbance was measured at $590 \mathrm{nM}$ in a Tecan Spark 10M plate reader.

\section{ACKNOWLEDGMENTS}

We thank T. Wolpert and J. Chang for helpful discussions and critical reading of this manuscript, J. Chang for providing the $a v r R p m 1_{\text {promoter }}: g f p$ reporter plasmid, W. Gassmann for providing DC3000 $\Delta c m a A \Delta c f a 6$ and DC3000 expressing avrRpt2, and G. Martin for providing $\Delta h r c C$ strain and the anti-AvrPto antibody. We thank S. Turner for assistance in maintaining suspension cell cultures.

\section{LITERATURE CITED}

Abramovitch, R. B., Anderson, J. C., and Martin, G. B. 2006. Bacterial elicitation and evasion of plant innate immunity. Nat. Rev. Mol. Cell Biol. 7:601-611.

Allwood, J. W., Clarke, A., Goodacre, R., and Mur, L. A. 2010. Dual metabolomics: A novel approach to understanding plant-pathogen interactions. Phytochemistry 71:590-597.

Anderson, J. C., Bartels, S., González Besteiro, M. A., Shahollari, B., Ulm, R., and Peck, S. C. 2011. Arabidopsis MAP kinase phosphatase 1 (AtMKP1) negatively regulates MPK6-mediated PAMP responses and resistance against bacteria. Plant J. 67:258-268.

Anderson, J. C., Wan, Y., Kim, Y.-M., Pasa-Tolic, L., Metz, T. O., and Peck, S. C. 2014. Decreased abundance of type III secretion system-inducing signals in Arabidopsis mkpl enhances resistance against Pseudomonas syringae. Proc. Natl. Acad. Sci. U.S.A. 111:6846-6851.

Apostol, I., Heinstein, P. F., and Low, P. S. 1989. Rapid stimulation of an oxidative burst during elicitation of cultured plant cells: Role in defense and signal transduction. Plant Physiol. 90:109-116.

Axelos, M. 1992. A protocol for transient gene expression in Arabidopsis thaliana protoplasts isolated from cell suspension cultures. Plant Physiol. Biochem. 30:123-128.

Benschop, J. J., Mohammed, S., O’Flaherty, M., Heck, A. J. R., Slijper, M., and Menke, F. L. H. 2007. Quantitative phosphoproteomics of early elicitor signaling in Arabidopsis. Mol. Cell. Proteomics 6:1198-1214.

Bigeard, J., Colcombet, J., and Hirt, H. 2015. Signaling mechanisms in pattern-triggered immunity (PTI). Mol. Plant 8:521-539.

Brooks, D. M., Hernández-Guzmán, G., Kloek, A. P., Alarcón-Chaidez, F., Sreedharan, A., Rangaswamy, V., Peñaloza-Vázquez, A., Bender, C. L., and Kunkel, B. N. 2004. Identification and characterization of a welldefined series of coronatine biosynthetic mutants of Pseudomonas syringae pv. tomato DC3000. Mol. Plant-Microbe Interact 17:162-174.

Büttner, D., and He, S. Y. 2009. Type III protein secretion in plant pathogenic bacteria. Plant Physiol. 150:1656-1664.

Cecchini, N. M., Monteoliva, M. I., Blanco, F., Holuigue, L., and Alvarez, M. E. 2009. Features of basal and race-specific defences in photosynthetic Arabidopsis thaliana suspension cultured cells. Mol. Plant Pathol. 10:305-310.

Chang, J. H., Urbach, J. M., Law, T. F., Arnold, L. W., Hu, A., Gombar, S., Grant, S. R., Ausubel, F. M., and Dangl, J. L. 2005. A high-throughput, near-saturating screen for type III effector genes from Pseudomonas syringae. Proc. Natl. Acad. Sci. U.S.A. 102:2549-2554.

Chen, L.-Q., Hou, B.-H., Lalonde, S., Takanaga, H., Hartung, M. L., Qu, X.-Q., Guo, W.-J., Kim, J.-G., Underwood, W., Chaudhuri, B., Chermak, D., Antony, G., White, F. F., Somerville, S. C., Mudgett, M. B., and Frommer, W. B. 2010. Sugar transporters for intercellular exchange and nutrition of pathogens. Nature 468:527-532. 
Chong, J., Soufan, O., Li, C., Caraus, I., Li, S., Bourque, G., Wishart, D. S., and Xia, J. 2018. MetaboAnalyst 4.0: Towards more transparent and integrative metabolomics analysis. Nucleic Acids Res. 46 (W1): W486-W494.

Cormack, B. P., Valdivia, R. H., and Falkow, S. 1996. FACS-optimized mutants of the green fluorescent protein (GFP). Gene 173:33-38.

Crabill, E., Joe, A., Block, A., van Rooyen, J. M., and Alfano, J. R. 2010. Plant immunity directly or indirectly restricts the injection of type III effectors by the Pseudomonas syringae type III secretion system. Plant Physiol. 154:233-244.

Felix, G., Duran, J. D., Volko, S., and Boller, T. 1999. Plants have a sensitive perception system for the most conserved domain of bacterial flagellin. Plant J. 18:265-276.

Fiehn, O., Wohlgemuth, G., Scholz, M., Kind, T., Lee, D. Y., Lu, Y., Moon, S., and Nikolau, B. 2008. Quality control for plant metabolomics: Reporting MSI-compliant studies. Plant J. 53:691-704.

Finnegan, T., Steenkamp, P. A., Piater, L. A., and Dubery, I. A. 2016. The lipopolysaccharide-induced metabolome signature in Arabidopsis thaliana reveals dynamic reprogramming of phytoalexin and phytoanticipin pathways. PLoS One 11:e0163572.

Gimenez-Ibanez, S., Hann, D. R., Ntoukakis, V., Petutschnig, E., Lipka, V., and Rathjen, J. P. 2009. AvrPtoB targets the LysM receptor kinase CERK1 to promote bacterial virulence on plants. Curr. Biol. 19:423-429.

Gómez-Gómez, L., and Boller, T. 2000. FLS2: An LRR receptor-like kinase involved in the perception of the bacterial elicitor flagellin in Arabidopsis. Mol. Cell 5:1003-1011.

Henry, E., Toruño, T. Y., Jauneau, A., Deslandes, L., and Coaker, G. 2017. Direct and indirect visualization of bacterial effector delivery into diverse plant cell types during infection. Plant Cell 29:1555-1570.

Hirano, S. S., and Upper, C. D. 2000. Bacteria in the leaf ecosystem with emphasis on Pseudomonas syringae-a pathogen, ice nucleus, and epiphyte. Microbiol. Mol. Biol. Rev. 64:624-653.

Huynh, T. V., Dahlbeck, D., and Staskawicz, B. J. 1989. Bacterial blight of soybean: Regulation of a pathogen gene determining host cultivar specificity. Science 245:1374-1377.

Kaffarnik, F. A., Jones, A. M., Rathjen, J. P., and Peck, S. C. 2009. Effector proteins of the bacterial pathogen Pseudomonas syringae alter the extracellular proteome of the host plant, Arabidopsis thaliana. Mol. Cell. Proteomics 8:145-156.

Kovach, M. E., Elzer, P. H., Hill, D. S., Robertson, G. T., Farris, M. A., Roop, R. M., 2nd, and Peterson, K. M. 1995. Four new derivatives of the broad-host-range cloning vector pBBR1MCS, carrying different antibiotic-resistance cassettes. Gene 166:175-176.

Kunkel, B. N., Bent, A. F., Dahlbeck, D., Innes, R. W., and Staskawicz, B. J 1993. RPS2, an Arabidopsis disease resistance locus specifying recognition of Pseudomonas syringae strains expressing the avirulence gene avrRpt2. Plant Cell 5:865-875.

Kunze, G., Zipfel, C., Robatzek, S., Niehaus, K., Boller, T., and Felix, G. 2004. The $\mathrm{N}$ terminus of bacterial elongation factor $\mathrm{Tu}$ elicits innate immunity in Arabidopsis plants. Plant Cell 16:3496-3507.

Lovelace, A. H., Smith, A., and Kvitko, B. H. 2018. Pattern-triggered immunity alters the transcriptional regulation of virulence-associated genes and induces the sulfur starvation response in Pseudomonas syringae pv. tomato DC3000. Mol. Plant-Microbe Interact 31:750-765.

Macho, A. P. 2015. Subversion of plant cellular functions by bacterial typeIII effectors: Beyond suppression of immunity. New Phytol. 210:51-57.

Macho, A. P., and Zipfel, C. 2014. Plant PRRs and the activation of innate immune signaling. Mol. Cell 54:263-272.

Mathieu, Y., Armen, K., Xia, H., Guern, J., Koller, A., Spiro, M. D., O’Neill, M., Albersheim, P., and Darvill, A. 1991. Membrane responses induced by oligogalacturonides in suspension-cultured tobacco cells. Plant J. 1:333-343.

McClerklin, S. A., Lee, S. G., Harper, C. P., Nwumeh, R., Jez, J. M., and Kunkel, B. N. 2018. Indole-3-acetaldehyde dehydrogenase-dependent auxin synthesis contributes to virulence of Pseudomonas syringae strain DC3000. PLoS Pathog. 14:e1006811.

Mercx, S., Tollet, J., Magy, B., Navarre, C., and Boutry, M. 2016. Gene inactivation by CRISPR-Cas9 in Nicotiana tabacum BY-2 suspension cells. Front. Plant Sci. 7:40.

Miller, W. G., Leveau, J. H., and Lindow, S. E. 2000. Improved $g f p$ and inaZ broad-host-range promoter-probe vectors. Mol. Plant-Microbe Interact 13:1243-1250.

Misra, B. B., de Armas, E., and Chen, S. 2016. Differential metabolomic responses of PAMP-triggered immunity and effector-triggered immunity in Arabidopsis suspension cells. Metabolomics 12:61.

Moroz, N., Fritch, K. R., Marcec, M. J., Tripathi, D., Smertenko, A., and Tanaka, K. 2017. Extracellular alkalinization as a defense response in potato cells. Front. Plant Sci. 8:32.
Navarro, L., Zipfel, C., Rowland, O., Keller, I., Robatzek, S., Boller, T., and Jones, J. D. 2004. The transcriptional innate immune response to flg22. Interplay and overlap with Avr gene-dependent defense responses and bacterial pathogenesis. Plant Physiol. 135:1113-1128.

Nobori, T., Velásquez, A. C., Wu, J., Kvitko, B. H., Kremer, J. M., Wang, Y., He, S. Y., and Tsuda, K. 2018. Transcriptome landscape of a bacterial pathogen under plant immunity. Proc. Natl. Acad. Sci. U.S.A. 115: E3055-E3064.

Noutoshi, Y., Okazaki, M., Kida, T., Nishina, Y., Morishita, Y., Ogawa, T., Suzuki, H., Shibata, D., Jikumaru, Y., Hanada, A., Kamiya, Y., and Shirasu, K. 2012. Novel plant immune-priming compounds identified via high-throughput chemical screening target salicylic acid glucosyltransferases in Arabidopsis. Plant Cell 24:3795-3804.

Nühse, T. S., Peck, S. C., Hirt, H., and Boller, T. 2000. Microbial elicitors induce activation and dual phosphorylation of the Arabidopsis thaliana MAPK 6. J. Biol. Chem. 275:7521-7526.

O'Brien, J. A., Daudi, A., Finch, P., Butt, V. S., Whitelegge, J. P., Souda, P., Ausubel, F. M., and Bolwell, G. P. 2012. A peroxidase-dependent apoplastic oxidative burst in cultured Arabidopsis cells functions in MAMP-elicited defense. Plant Physiol. 158:2013-2027.

Ogawa, Y., Sakurai, N., Oikawa, A., Kai, K., Morishita, Y., Mori, K., Moriya, K., Fujii, F., Aoki, K., Suzuki, H., Ohta, D., Saito, K., and Shibata, D. 2012. High-throughput cryopreservation of plant cell cultures for functional genomics. Plant Cell Physiol. 53:943-952.

Oh, H. S., Park, D. H., and Collmer, A. 2010. Components of the Pseudomonas syringae type III secretion system can suppress and may elicit plant innate immunity. Mol. Plant-Microbe Interact 23: 727-739.

Park, E., Lee, H.-Y., Woo, J., Choi, D., and Dinesh-Kumar, S. P. 2017. Spatiotemporal monitoring of Pseudomonas syringae effectors via type III secretion using split fluorescent protein fragments. Plant Cell 29: 1571-1584

Peck, S. C., Nühse, T. S., Hess, D., Iglesias, A., Meins, F., and Boller, T. 2001. Directed proteomics identifies a plant-specific protein rapidly phosphorylated in response to bacterial and fungal elicitors. Plant Cell 13:1467-1475.

Peñaloza-Vázquez, A., Preston, G. M., Collmer, A., and Bender, C. L. 2000. Regulatory interactions between the Hrp type III protein secretion system and coronatine biosynthesis in Pseudomonas syringae pv. tomato DC3000. Microbiology 146:2447-2456.

Rahme, L. G., Mindrinos, M. N., and Panopoulos, N. J. 1991. Genetic and transcriptional organization of the hrp cluster of Pseudomonas syringae pv. phaseolicola. J. Bacteriol. 173:575-586.

Rico, A., and Preston, G. M. 2008. Pseudomonas syringae pv. tomato DC3000 uses constitutive and apoplast-induced nutrient assimilation pathways to catabolize nutrients that are abundant in the tomato apoplast. Mol. Plant-Microbe Interact 21:269-282.

Roschzttardtz, H., Séguéla-Arnaud, M., Briat, J.-F., Vert, G., and Curie, C. 2011. The FRD3 citrate effluxer promotes iron nutrition between symplastically disconnected tissues throughout Arabidopsis development. Plant Cell 23:2725-2737.

Salmeron, J. M., and Staskawicz, B. J. 1993. Molecular characterization and hrp dependence of the avirulence gene avrPto from Pseudomonas syringae pv. tomato [corrected]. Mol. Gen. Genet. 239:6-16.

Schenke, D., Böttcher, C., and Scheel, D. 2011. Crosstalk between abiotic ultraviolet-B stress and biotic (flg22) stress signalling in Arabidopsis prevents flavonol accumulation in favor of pathogen defence compound production. Plant Cell Environ. 34:1849-1864.

Segonzac, C., and Zipfel, C. 2011. Activation of plant pattern-recognition receptors by bacteria. Curr. Opin. Microbiol. 14:54-61.

Tang, X., Xiao, Y., and Zhou, J. M. 2006. Regulation of the type III secretion system in phytopathogenic bacteria. Mol. Plant-Microbe Interact 19:1159-1166.

Toruño, T. Y., Stergiopoulos, I., and Coaker, G. 2016. Plant-pathogen effectors: Cellular probes interfering with plant defenses in spatial and temporal manners. Annu. Rev. Phytopathol. 54:419-441.

Ward, J. L., Forcat, S., Beckmann, M., Bennett, M., Miller, S. J., Baker, J. M., Hawkins, N. D., Vermeer, C. P., Lu, C., Lin, W., Truman, W. M., Beale, M. H., Draper, J., Mansfield, J. W., and Grant, M. 2010. The metabolic transition during disease following infection of Arabidopsis thaliana by Pseudomonas syringae pv. tomato. Plant J. 63:443-457.

Wright, C. A., and Beattie, G. A. 2004. Pseudomonas syringae pv. tomato cells encounter inhibitory levels of water stress during the hypersensitive response of Arabidopsis thaliana. Proc. Natl. Acad. Sci U.S.A. 101:3269-3274.

Xin, X. F., and He, S. Y. 2013. Pseudomonas syringae pv. tomato DC3000: A model pathogen for probing disease susceptibility and hormone signaling in plants. Annu. Rev. Phytopathol. 51:473-498. 
Xin, X.-F., Nomura, K., Aung, K., Velásquez, A. C., Yao, J., Boutrot, F., Chang, J. H., Zipfel, C., and He, S. Y. 2016. Bacteria establish an aqueous living space in plants crucial for virulence. Nature 539: 524-529.

Zeidler, D., Zähringer, U., Gerber, I., Dubery, I., Hartung, T., Bors, W., Hutzler, P., and Durner, J. 2004. Innate immunity in Arabidopsis thaliana: Lipopolysaccharides activate nitric oxide synthase (NOS) and induce defense genes. Proc. Natl. Acad. Sci. U.S.A. 101: 15811-15816.

Zhang, J., and Zhou, J. M. 2010. Plant immunity triggered by microbial molecular signatures. Mol. Plant 3:783-793.
Zipfel, C., Kunze, G., Chinchilla, D., Caniard, A., Jones, J. D. G., Boller, T., and Felix, G. 2006. Perception of the bacterial PAMP EF-Tu by the receptor EFR restricts agrobacterium-mediated transformation. Cell 125:749-760.

Zipfel, C., Robatzek, S., Navarro, L., Oakeley, E. J., Jones, J. D. G., Felix, G., and Boller, T. 2004. Bacterial disease resistance in Arabidopsis through flagellin perception. Nature 428:764-767.

AUTHOR-RECOMMENDED INTERNET RESOURCE

Metabolomics Workbench database: www.metabolomicsworkbench.org 